\title{
Statistical Analysis of Fuel Rod Scans
}

\author{
Martin S. Zucker \\ Iester G. Epel
}

Technical Support Organization Brookhaven National Labojacory Upton, New York 11973

June 1971

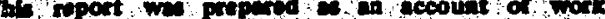

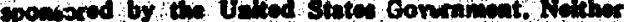

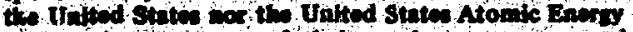

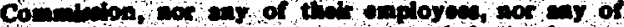

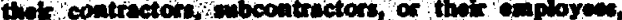

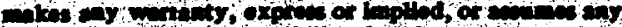

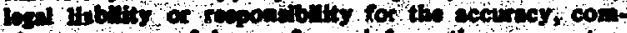

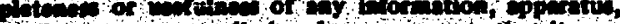

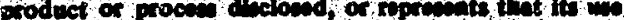

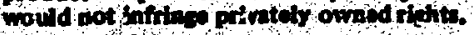




\section{statistical Analysis of Fuel Rod Scans}

By: Martin S . Zucker

Lester G. EpeI

Technical support Organization

Brookhaven Iational Laboratory

\section{Ibstract}

Gamma scanning of fuel rods containing plut onium has gained acceptance as a way of de termining the uniformity of fual loading and, to a lesser extent, the total amount of material. The usual electronlcs for making these measurements Includes an analogue ratemeter driving a otrip chart recorder. Tho resulting strip chart recording is hard to interpret in more than a qualitative manner. The us, rocontly, of a digital ratemoter in a rad canning apparatú. has made statistlcal analysis of the data much more convenlent ana prompted such an analysls to be made. The following ana lyses were performed. (1) A test to see whether at 1 dast one segment of the rod differed signiflcantl, $(1, e$, with some fonfidence limit) from the rest, of the rod, (2) As ruming that the rod falled test (1) for homogenelty, the segmonts were ranked into groups whidh are otatistica liy honogeneous within themselves, (3) An attemet to find periodicities in the rod due to its internal etructure.

Additiona 11y, use was made of the gamma opectra of the whole rod ab recorded by a mult channe 1 andlyzer aurling the rod rans to try to determine whother o $1 \mathrm{ghifi}$ cant difforonces In lsotoplc compos tion could be found sotimatos were made of tho contrlbution to the counting rato coming from that part of the rod chadowed by the roanning elits. 


\section{introauction}

soiniling the nuclear radiation emitted by fuel rods has

gilned acceptance as a way of determining the uniformity of the loading and, to a lesser extent, the total amount of material present. Such apparatus can and has been used to indicate gros, defects, e, g., missing pellets, or pellets of completely abnomal composition. Attempts to be quantitative have been mad but with uncertain results, due to the difflculties inpolved in interpreting the strip chart recording in anything pre than a semi-quantitative manner. A basic problem ls that the otrip chart recoraing, in the form of a continuous analogue 1gnal, has folded into it such effects as the time constant of the analogue ratemeter, the recorder slewing response, and the random statistical fluctuations in the count rate, and these aro difficult to disentangle from the response due to a possible non-uniformity in the fuel rod. A practical difficlity with the uspal otrip chart recoraling $110 s$ in the tediousness of extractIog numerical Information that one can use to do gtatlstical analyols.

In a recont rod scanning exercise, the electronic equipment Included a digltal ratemeter rather than the ugual analogue device. (1) This removed some of the above theoretical and practlcal difficulties and made data acquísition so (relatively) arey that on attack on a question or 1 ong standing was prompted, 
namely, what quantitative statistical meaning can be placed on such scanning measurements.

The feature of digital ratemeters which facilitated the present measurements is that it sums up all the counts tecelved in a given preset time interval while making available for readout the results of the previous time interval. The fact that the readout represents the sun of the counts over $a$ fint te time interval gets rid of most of the lnstantaneous fluctuations characteristic of analogue ratemeters wishnt the necessity of introducing a large time constant, which might cause a defect in the rod to be obscured. In princlpte the counts per time interval (equivalent to the counts received from a corresponding length of rod) coula be read out automatically with some printing device. In the present instapce, the values were read out wisually and recorded by hand; this did limit the total amount of data which could be takien.

The analyois of the data and 1 ts interpretation are tentative and is presented here on that basis in ordar to expose it to comment. 
1010re discusping these results the actial apparatus will 10 degeribed, the rod scanner is 11 lustrated in Fig. 1. The rods themselver, consisting of sintered $\mathrm{PuO}_{2}-\mathrm{UO}_{2}$ pellets ( IOg

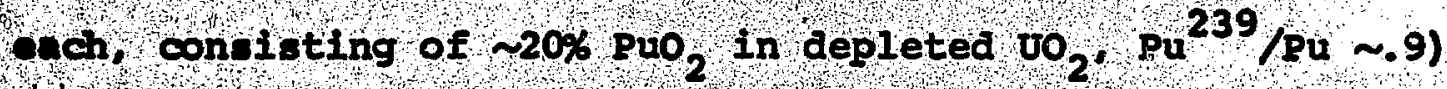
12 ptainless tubing and having dimensions as indicated in Fig. 2 , were hold In an aluminum angle carrier and noved at a constant uped by a eynchronous motor driven rack and pinion past a photomultiplier with an interposed 2 in.-thick lead colilmator. The photomult 1 plfer was shielded from the rest of the rod and Erom room background by additional shielding, not shown. The Individual pellets were apprr ximately $5 / 8^{\prime}$ long by $7 / 8^{\prime \prime}$ in dlameter, somewhat dished at each end, but otherwise cylindrical. The rod was noved at $1.2 \mathrm{in} / \mathrm{min} .=0.02 \mathrm{in} / \mathrm{s}$. The blit width was $13 \mathrm{~mm} \sim .12$ in. Approximately $1 / 5$ of the length of a pellet - ovea past the silt (whose wiath was itself about $1 / 5$ of a pelIet in length) in 6 seconds (the integration time choser for the algital ratemeter). Thus, even aside from the effect of penumbra, there 18 a certain amount of "ruming averaging" as the scan proceeds, which tends to deemphasize any differences between nolghboring peliets. This point will be of particular significance later.

The electronics used in this experiment are functionally 


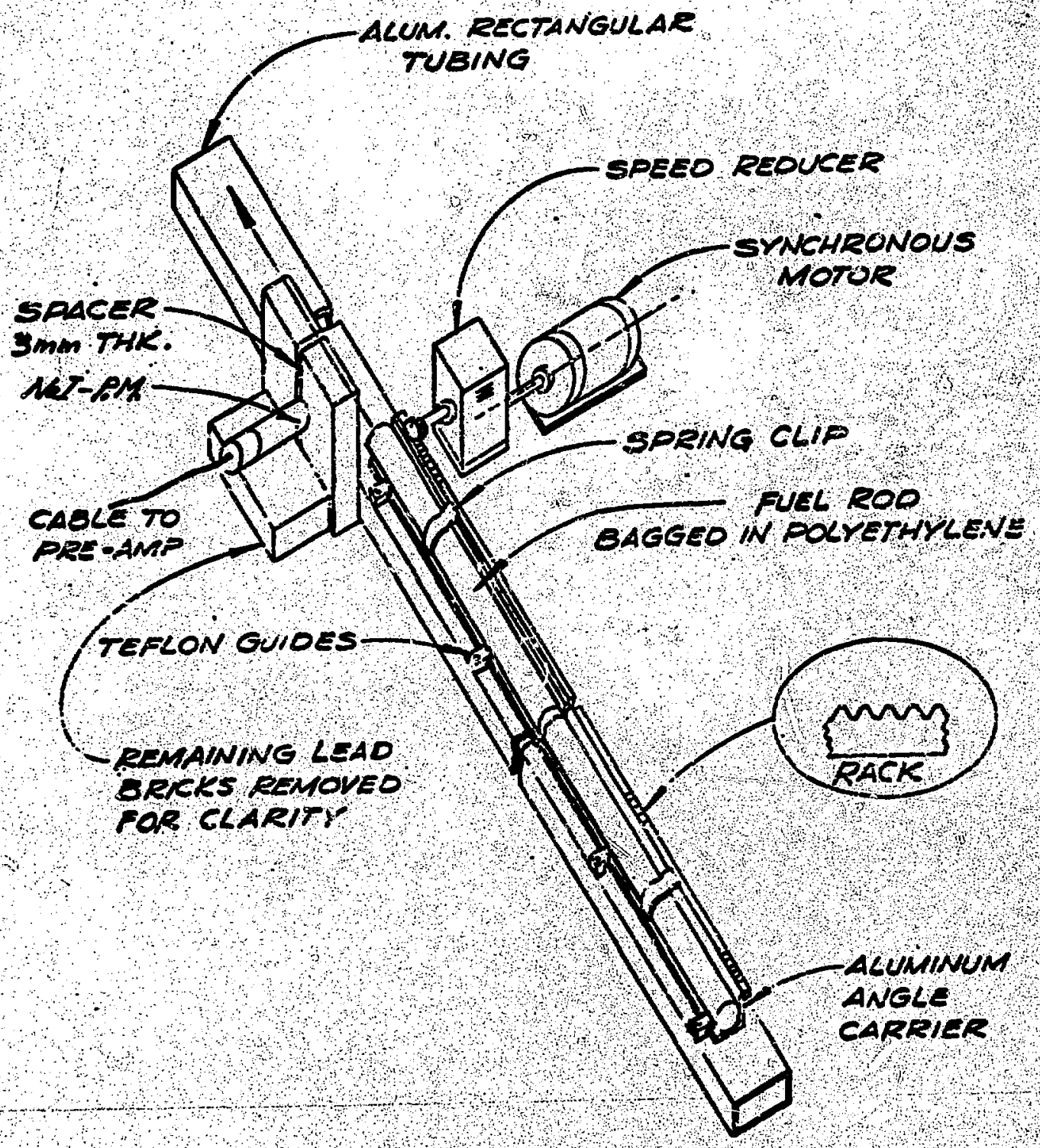

FUEL ROD SCANNER 

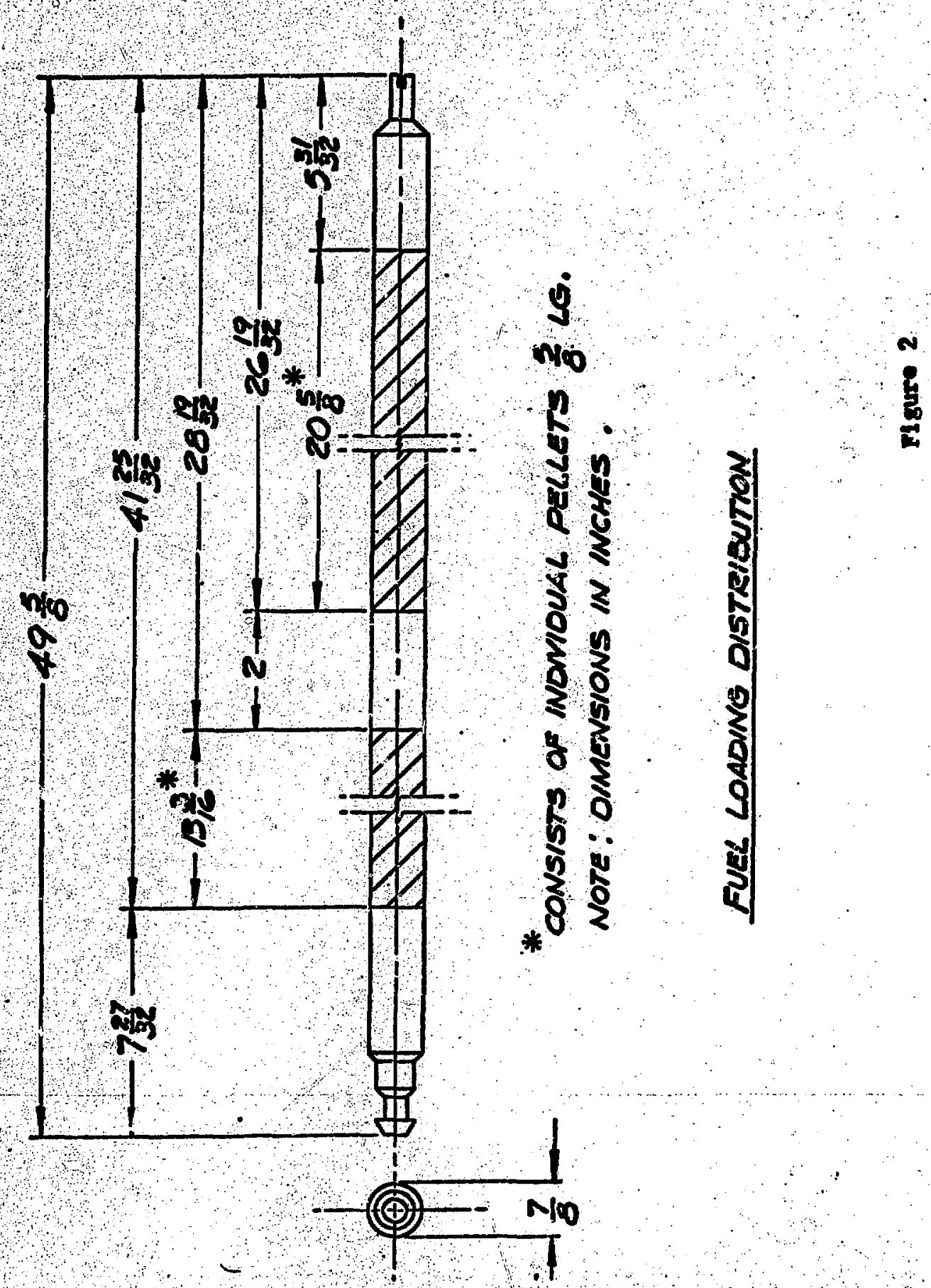
as indicated in Fig. 3. The equipment is essentialiy the same as has been used before with the same scanning apparatus but with the noted exception of the digital rather than analogue ratemeter. The single channel analyzer condition preceding the ratemeter was set to encompass both the $208 \mathrm{keV}$ peak and the $380 \mathrm{keV}$ complex," while the mult lchannel analyzer included the $60 \mathrm{keV}$ $\mathrm{Am}^{241}$ and some $\mathrm{X}$-ray peaks as wel1. As mentioned before, the digital ratemeter was set to sum up lts input counts over successive 6 second intervals ( -12 in. of rod), while the multichannel aralyzer accuinulated spectrum from the whole fiel rod, beling manually gated on and off in accordance with the atrip chart trace indicating the beginning and end of the fuel rod. This latter operation could be done with a precision of $\sim 1 / 300$. A run inalcated the background to be about $(4-5) \%$ in the vialnIty of the $208 \mathrm{keV}$ peak and the highest portions of the $380 \mathrm{keV}$ complex.

The strip chart record reveals in a crudely quantitative way several features of the scanning apparatus which have a bearing on interpreting the statistical results to be alscussed. The general nature of the strip chart trace is shown in Fig. 4, which is of a dummy rod with one pellet deliberately replaced with a depleted $\mathrm{vO}_{2}$ pellet. Except in the nelghborhood of the dumy pellot, the trace seems flat except for 



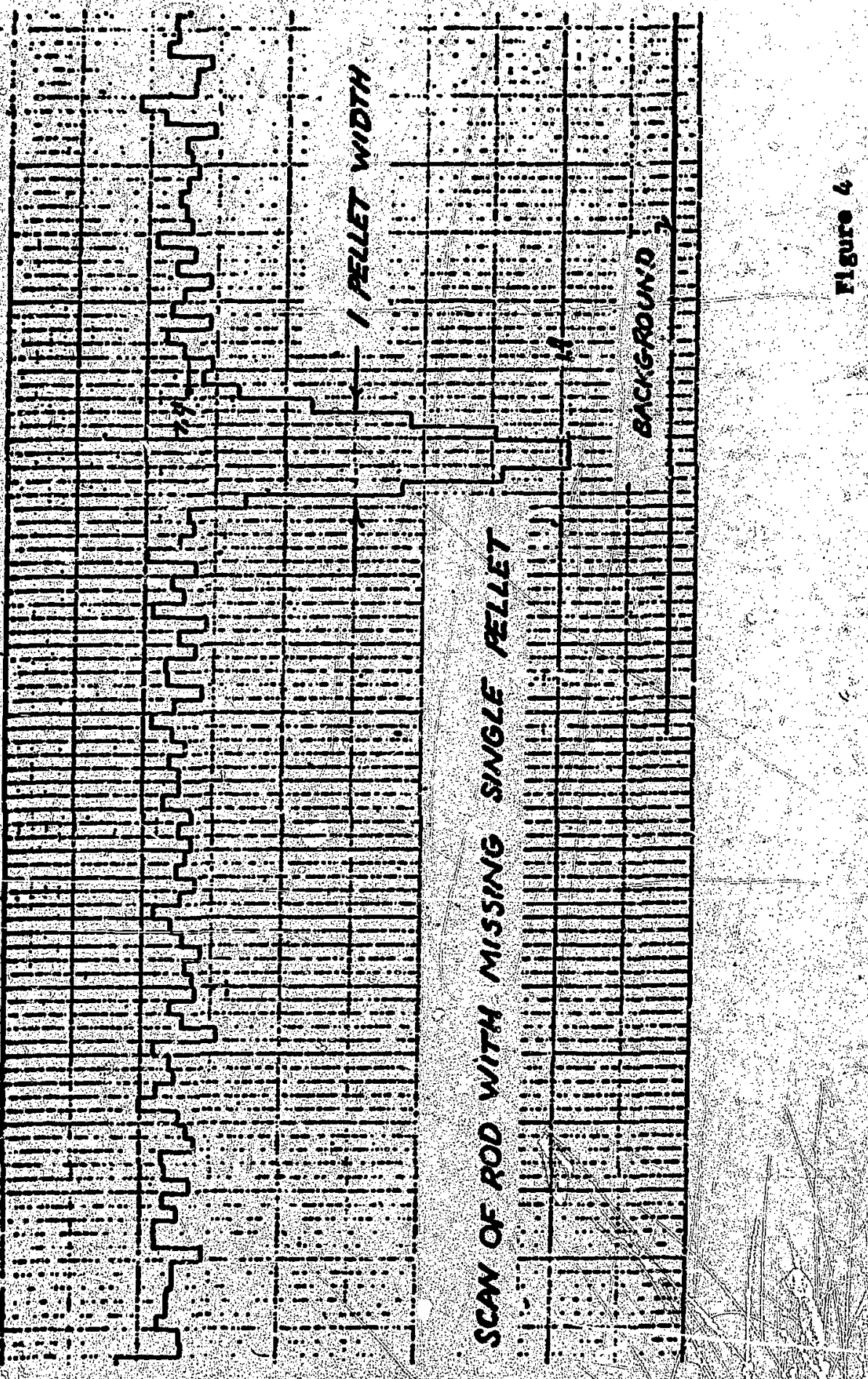


statlstical fluctuations. Corresponding to the missing pellet the trace alps $(7,4-1,8) /(7,4,2)$, $78 \%$ from its average level and the full width at half maximum $(-, 6$ \%) corresponds well to the longth of a pellet. It is not clear from this alone Wf ther the remainder abuve background is aue to the rest of tho rod ghining through the shielding. Fig. $5 a$ shows the trace of 2 normal fuel $\mathrm{rod}$ at the end of the loading, fig. $5 \mathrm{~b}$ shows the bcan of the same rod near the central region where there I. no fuel loading. studying these two traces it is possible to entimate that the rest of the rod contributes something like $(4.2-3.7) /(4.2-6) \sim 14 \%$ to the count received from the pellet juet in front of the slit. Judging from the way the contributions adatogether in the region of the central unloaded section, only about two inches of rod on either side of the slit contripute to the counting rate recelved from that part of the rod immediate $1 Y$ in front of the $s 11 \mathrm{t}$.

For comparison with the above (which could be called "digita" strip chart recordings), Fig, 6 shows the more usual "analogue' strip chart scan of the same type of rod, in the nelghborhood of the unloaded miadle and with some deficient pellets. While not identical, the experiment resulting in this plot is quite comparabie to the present one. (2) the aifFlculties in reducing this record to data guitable for analysis 


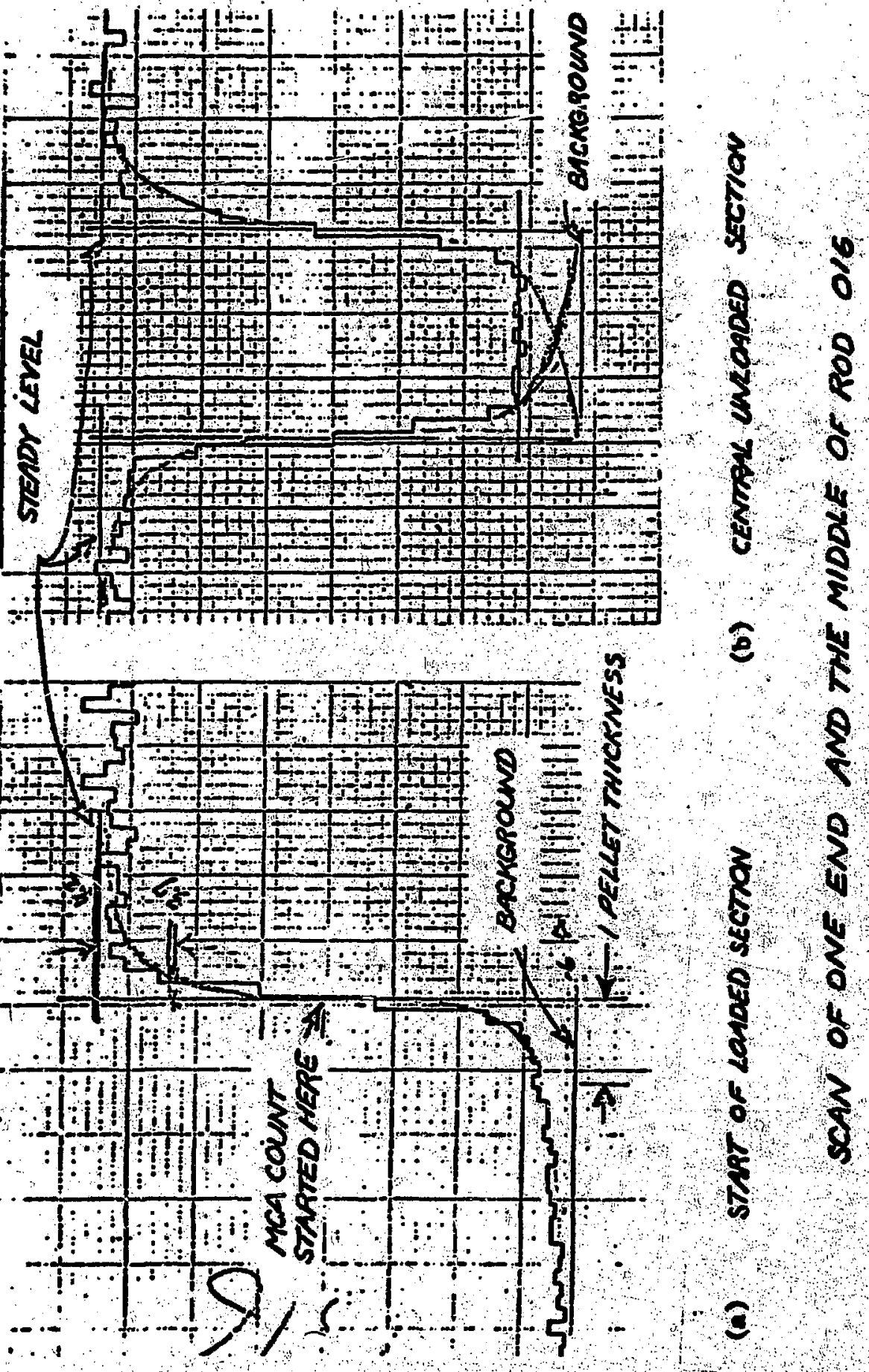



1s evident. Even the answer to the question of the number of deficient pellets would be uncertain because of the way statistical fluctuations in the count rate are tied in with the time constant of the response of the ratemeter and the recorder. If it were not for the fact that several deficient regions occur in the same rod even an Intercomparison (which leads to estimates of 4,2 , and 1 deficient pellets) could not have been made. 


\section{1. on way Inalysis of vartance}

The dlgital rate-cec had a vioual output which oniblet the counts collected during each six-second count Interval to bo (mnuaily) reconded for succebsive intervals of tine over fappectable lengths of the full rod being scanned. The sequence of uch mubere were divided into groups, ench oprresponding to a owomit of fuel rod of oqual length. Each meanurament of a particular group wa condidered a enpling from that eegient of the rca corvosponding to the group faseuning each seginent to be uniforw in (teelf). The bucieground, being anall and contant we not subtracted. Thus the moarurements fram a segnent of rod conetitutes a aple which wa compared with the eapele corpoponding to the other segmente of the rod to test for uniformity alow the rod. In waking wuch comparieone, meneurements of segmate of the rod known a priorl to euffer from various effects catranous to the fuel loading iteelf were excludeds for example, the regione adjacont to the and and the unloaded midale portion of the rod.

Itwe teet used to make this comparison we the "one way enalys of variance" (Xwovi) In wich the variance of the sample wane Is compared to the mons of the anple variances. The wrothenis tosted is that the $k$ amples (degments of fuel rod). 
each with $n$ measurements (the si $x$ second integrated counts) all have equal means. Although the procedure is predicated on the assumption that the samples are normally distributed and have equal variances, the method ls fairly "robust" and Insensitive to these conditions (Actually there 18 no reason to suspect that the data doesn't meet these prerequisites any$\operatorname{may}:)$

Data mainly from the otandard rod 016 , but also from rods 005 and 023, were used. since a contigrous sequence of approximately 125 measurements were made along the rod, the groupings into $k$ samples containing $n$ measurements each could be accomplished in veveral ways. Because 5 adjacent readinge constitute a pellet width, one "natural" grouping consinted of 25 samples of 5 observations each, though actually, there wasn't any convenient way to precisely synchronize the count with the actual location of each pellet, and as indicated previously. there is a fair amount of "averaging in" of adjacont readinga represented in any one measurement. The 5 by 25 and eight other partitions of the data shown in rable I were analyzed. The rovults of the Awov computation and the critical values of the I distribution at, the $5 \%$ level of eignificance (95\% confidence Ievel) are also listed there. The "between variance" (the varfance of the $k$ exple means) divided by the "within variance" 


\section{0.}

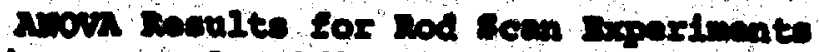
(one ury elnosifleation of varianos teot)

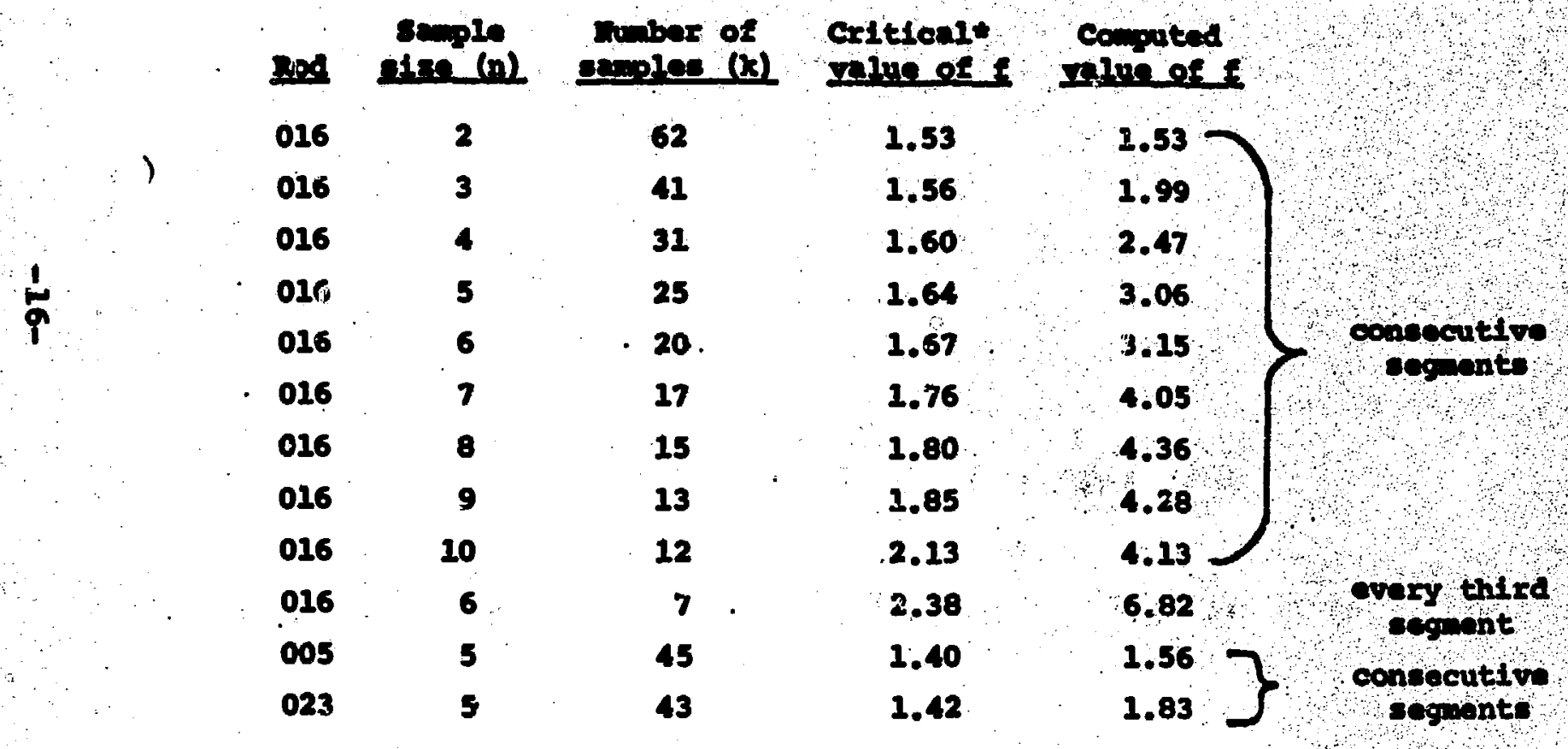

\footnotetext{
- for $\alpha=.05$ (95\% confidence inite).
} 
(which is the average variance of the $n$ observations within each of the samples) gives the f factor, $f=\left(s_{B}^{2} / s_{w}^{2}\right)$. This value computed from the data was then compared with the theoretical value of the random variable having the so called $f$ distribution with $(k-1)$ and $k(n-1)$ degrees of freedom at a confidence level of (1- $\alpha)$. If the means of all the samples were statistically equivalent (i.e., all segments of the rod essentially the same) then the calculated $f$ would be smaller than that corresponding to the confidence level $(1-\alpha)$. It is clear however from table I that (except for the $n=2, k=62$ case) the ratio of between variance to the within variance is always well into the critical region, and thus the segments Into which the rod were divided cannot be considered to all have the same mean.

As mentioned in the previous section, the observations of count rates for adjacent points are not entirely independent. because of the effect of neighboring points contributing to the particular point being observed at any time. This effect can only serve to decrease the between varfance compared to the Within variance and reduce the computed value of $f$. An esemile illustrating this can be seen in the eingle case shown in Table I (7 samplas of 6 obervatione each) where only every third readIng tron the digital ratameter was usod in the analysis. that is, 
two Intermediate observations between readings were discarded and the remaining observations were grouped into 7 samples In which the adjacent observations were essentially indepondont doterminations. It is seen that the computed $f$ value is further into the critical region for this case than tn those cases where the consecutive readings correspond to phyolcally adjacent points on the rod. Based on this consideration and the results show in Table I it may be said that the standard rod is not composed of statistically homogeneous segments along its ontire length.

As shown in rable I, similar tests were conducted on two other rods. On one rod the observations were partitioned Into 45 samples of 5 observations each; on the other rod the data was grouped into 43 samples of 5 observations each. These results also indicate that these rods are similarly composed of segments whose means are different in a statisticaliy elgnificant sense. 
2. $\chi^{2}$ Test of observed variances

The uuccessive readings taken in a rod scan contain

whatever variability the rod may have mixed in with whatever variance is induced by the equipment; in the present situation, drift in the "electronics" was chiefly suspect. To study this effect, the rod transport was stopped at an arbitrary point on the rod and successive counts for a fixed time interval recorded. The average count rate for 40 observations was found to be 1176 while the variance in these observations was 1367 .. If counting atatistics were solely involved (Poisson process) then the variance would be equal to the mean. It is thus tempting to attribute this difference to the contribution to the measured variance arising from instabilities in the electronics. However, the obgerved difference is not statistically significant since the $x^{2}$ value computed from the two estimates of the variance was 45 , and $95 \%$ of $\mathrm{X}^{2}$ values with $40-1=39$ degrees of freedom 11 e between 23 and 58.

3. The Multiple Range Test The awova test is indicative of whether there is inhomogenelty in the sample means, in this case each roprosenting - segment of the rod, but it alone gives no indication of how many or wich ones are not equal or by how wuch they fail to be. -qual. Duncan' a mitiple range test (DuR) will take a population 
prolouely provon inhomogeneous (as has been done in this case by the Arov test previously described) and separate the samples Into groups that are homogeneous within themselves, although not Wth one another, with some specified degree of confidence. The Dar tast $1 \mathrm{fm}$ to the difference allowed between any two sample means fot them to belong to the same homogeneous population. this aIfow range $1 \mathrm{~s}$ a function of the sample varlance, the desired level of significance, and the number of data points Involved. The allowed range (the least signiflcant range") 10 In fact the so called "least significant studentized range" at the desired level of significance multiplied by the standard orror of the means being tested for inclusion in the one subset. Using this range, a list of the sample means ordered as to size can be separated into subsets that are otatietically spoaking homogeneous within themselves. lable II is a listing of the ordered sample means from rod 016, grouped as indicated by the brackets, assuming a confidence level of $95 \%$.

other groupings would result if different confidence Iovels were demanded, or if certain of the means were omitted from consideration: As an example of the latter point, if the lowest 4 means are discounted, all of the adta can be roduced to only two internally homogeneous subsets. If, dditionally, the two highest means are discarded, the means 
shopets

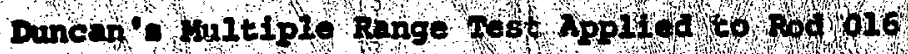

geginont in

$$
\text { \} }
$$$$
1
$$

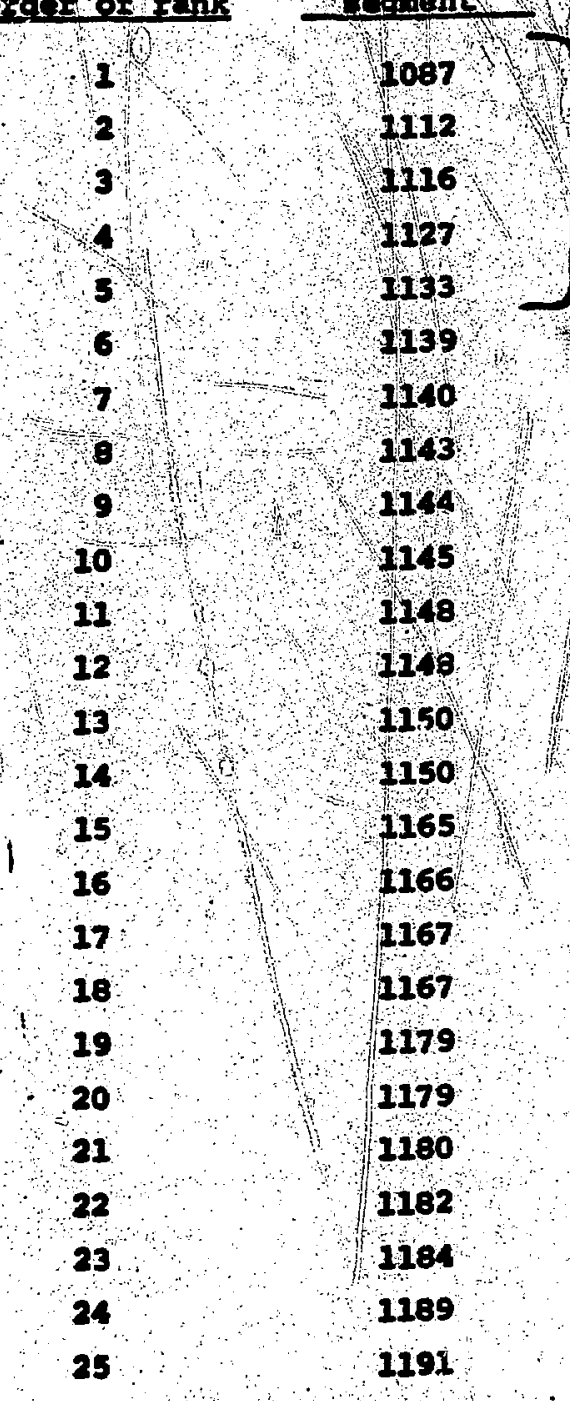

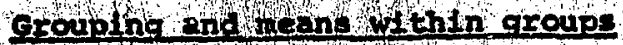

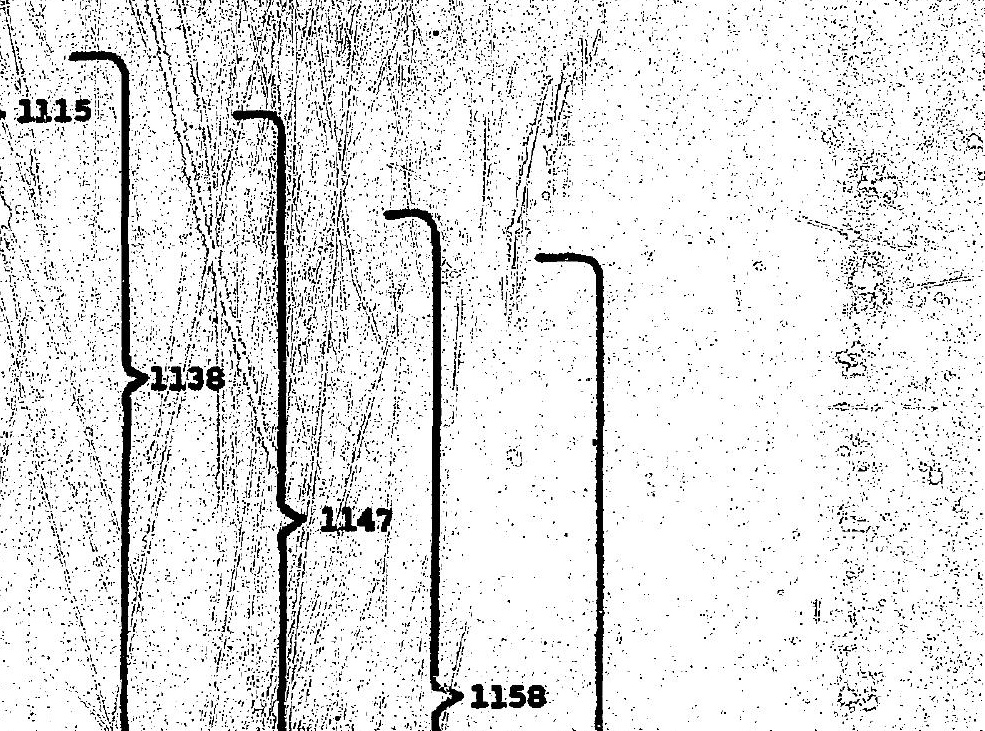

1163 
for the romaining 19 samples (segments) can be considered

Qqual at the 95\% confidence level. Discarding only the one

lowat wan yields 4 subsets. While the lirst two examples

mationed above were for the sake of lilustration, the last

hag a valld point to $1 t$, In that the segmext giving rise to

thif 10 value happens to be closer to the spacer in the rod the others in the set, and thus might be expected to in-

diate low. (10 other correlations with position were noticed.)

The 24 remaining mane then fall into 4 self-homogeneous sub-

cete. The value of the highest mean of these four subsets is

23 nigher than the mean of the lowest subset.

Thus the combination of ANOVA and DMR tests enable a reasonably guantitative statement to be made about the uniformity of this particular fuel rod. A scan of about half the fuel loading indicates that with $95 \%$ assurance, the rod was not homogmoous to the extent that the 24 segments that this part of the rod waf divided into, could be lumped into four self-homogeneous groupe such that the difference in means between the highest and 1dwat was about $2 \%$. Something about pellet homogeneity could be Inferred from this. Unfortunately the present apparatus did not allow a direct correlation between pellet identity and position along the rod, otherwise a stronger statement would be poentble. 
4. Attempt to Find periodicites in the scan

As previously mentioned the pellets are known to have slightly aished ends so that in principle it might be expected that a periodicity show up in the counts recelved during the six second count intervals, namely, every fifth reading should be somewhat depressed. In practice, it was expected that self-shielding might mask the effect at the level of counting statistics used $(-1200 \mathrm{cts} / 6 \mathrm{sec})$, however. because of curiosity the attempt was made anyway.

An autocorrelation function of the form

$$
c(T)=\sum_{I}^{n-T} f(t) f(t+T)
$$

was used. Here, $f(t)$ is the counting rate at position (six secona count interval) $t$ along the rod, and $t$, the 1 lag," is a shift $T$ time intervals along the rod. considering $c$ as a function of $T$, relative maxima are expocted to occur at values of $T$ which are integral multiples of any periodicity In the function $f(t)$, in the present instance periodicity of 5 might be expected.

The function $C(T)$ was computed on the basis of eow data pointe obtained from rod 016,100 values were und to computo c for Ings of 0 through 10 , olch su alugy gonoratod by the same number of term. The 11 suw thw obtalind ware 
averagod and the deviatlons from this average, $C(T)-C(T)$ ave, plottad as a function of $\mathrm{lag} \mathrm{(Fig.} 7$, curve 1). There is no ovidence of any periodicity. To estimate how much of an - ffect could have been detected if present, percentages of $10 \%$ and $20 \%$ were deducted from every fifth count and the cafculation $\mathrm{c}(\tau)$ repeated, giving curves 2 and 3 , respectively. Dedicting 10 and $20 \%$, respectively, for every third count resulted in curves 4 and 5 . The periodicities of 5 and 3 . artifleally induced in this way are clearly visible, indicatIng that a periodic deficiency (or enhancement) of as little ar 10\% and probably appreciably less could have been detected In this way. That no periodicity was detected presumably. is due to both the serf-shielding, and the lack of slificient statieticai precieion on the individual measurements compared to the total number available for the analyses.

5. Statistical Analysis of the Total Rod spectrum The multichannel analyzer (YCA) collacted a spetrum characteriatic of each whole rod scanned: A spectrum from the standard rod 016 run 2, shown in Fig. 8 is typical, yet there wre ceoming differencal between other runs of the eawe rod and of different rods. To decide whether these differences wre real, prellminary data reduction for the not counte In the $60 \mathrm{kov} \mathrm{m}^{241}$, the $200 \mathrm{kev} \mathrm{v}^{237}$, the $380 \mathrm{kev}$ complex, 


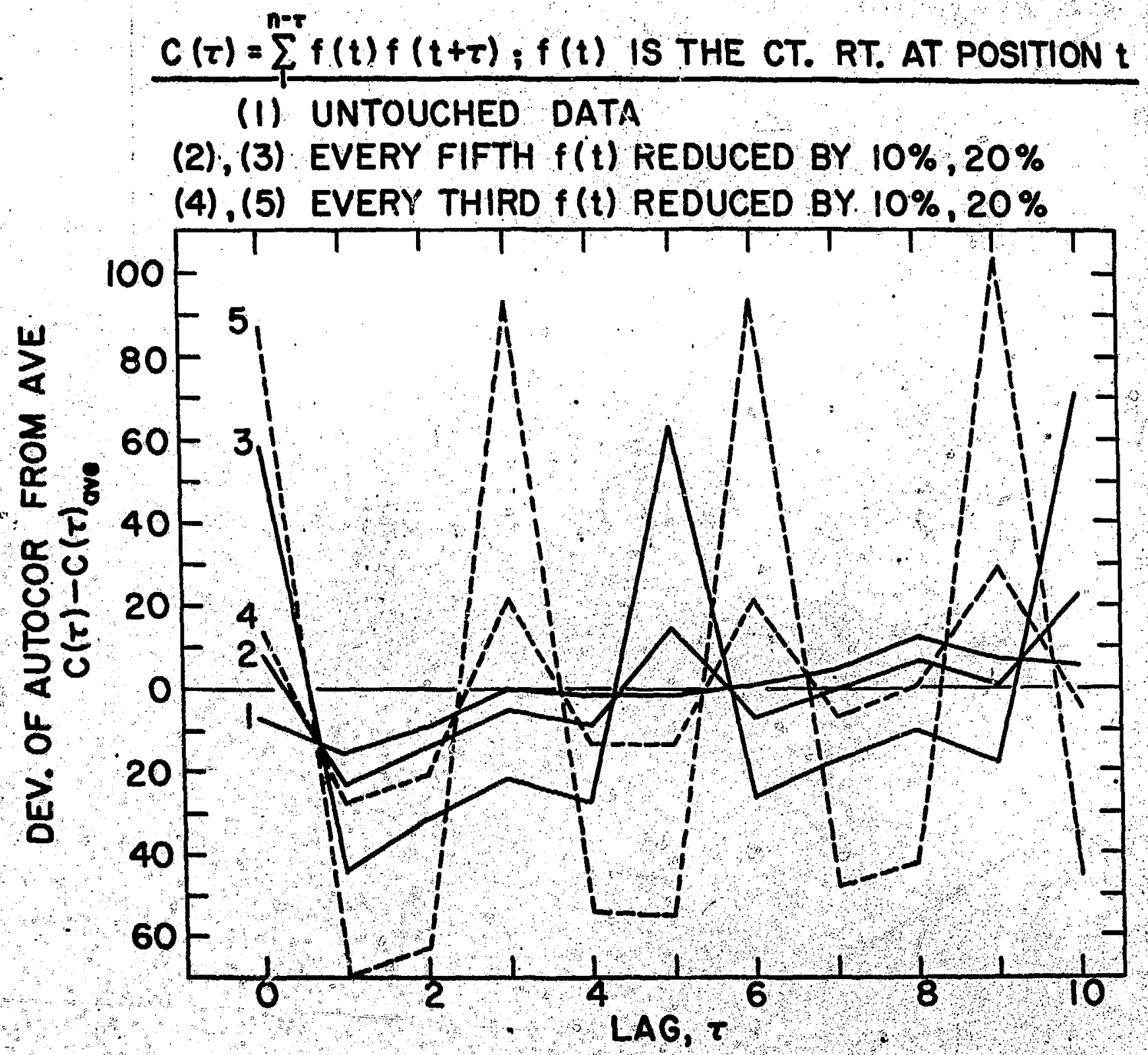




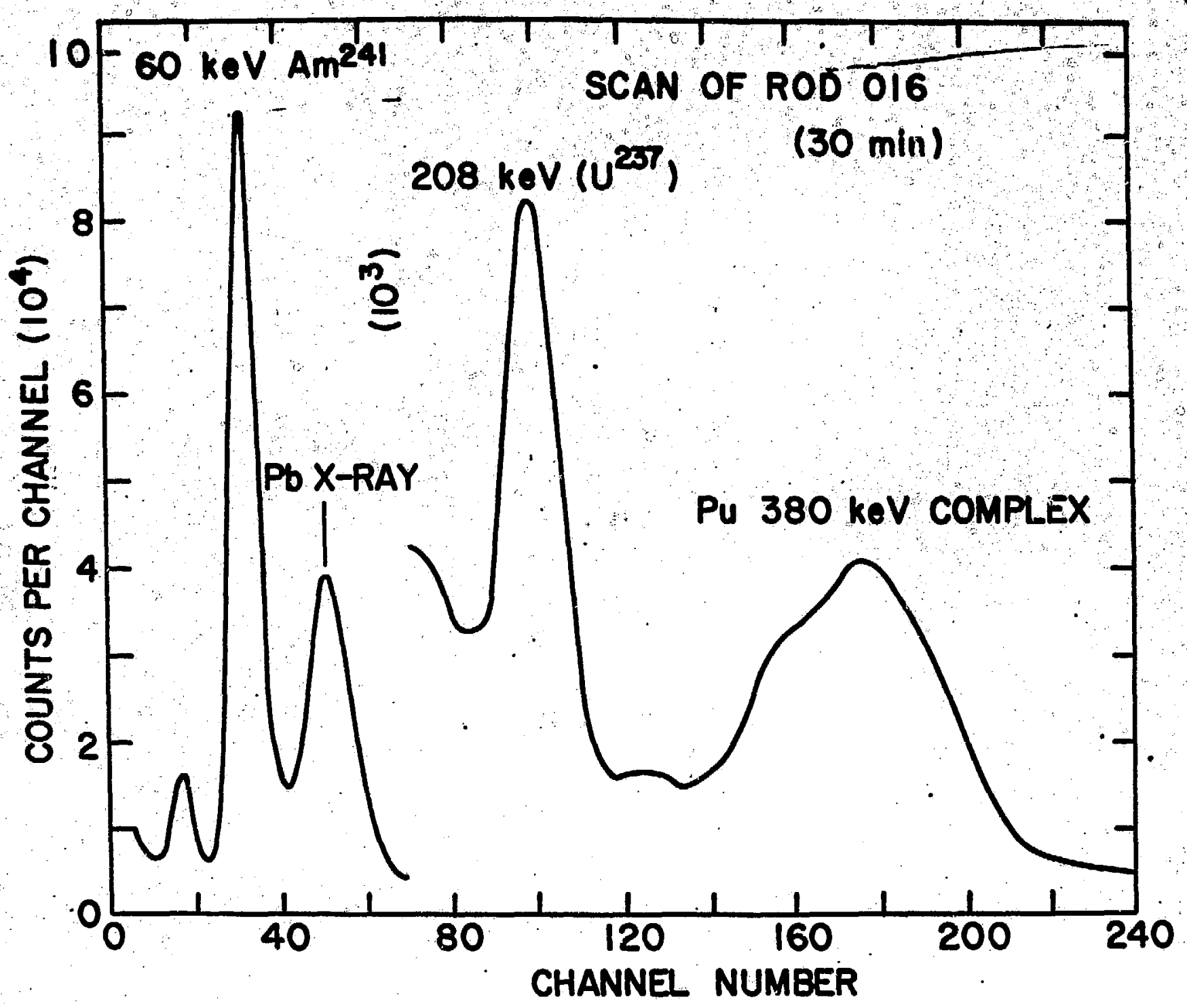

Frane 8 
and the $208 \mathrm{keV}+380 \mathrm{keV}$ complex was made for five of the runs, as listed in Table. III.

Using the $208 \mathrm{keV}$ or the $380 \mathrm{keV}$ complex, or both (as a groses count) as indications of Pu content, there is seen to be no reason to suspect any differences in total pu content, es-
pectally considering that there was, as mentioned previously.
a $1 / 300$ uncertainty in the timing of the ma runs.
However this carnot be said for the differences in $\mathrm{Am} 241$ content that are revealed by analysis of the total counts in the $60 \mathrm{keV} \mathrm{Am} 241$ peak. The statistical ouestion posed was. Whether the average of the $60 \mathrm{keV} \mathrm{Am} 241$ peaks in the three rune made with 016 was significantly different from the $60 \mathrm{keV}$ reault with rods 023 and 005 . The use of a student $t$ test indicated that this average was indoed different than the values. for the other two rode for a two-tailed test at the $95 x$ confldence level. (At the $99 \%$ confidence level, however, this average was agnificantly different from that of rod 023 only.) The $t$ test was mandated by the minll amount of data avaliable and was inplemented by conparing in turn the measured values for rods 023 and 005 with the mean of the throe meapuramante of 016. Since there wore only 3-1-2 degreas of frepdom, the allomed deviation wre quite largo-yot even these wore oxeconded. 
$\cos 1 \mathrm{xI}$

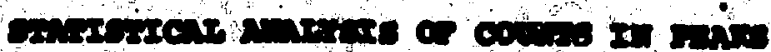

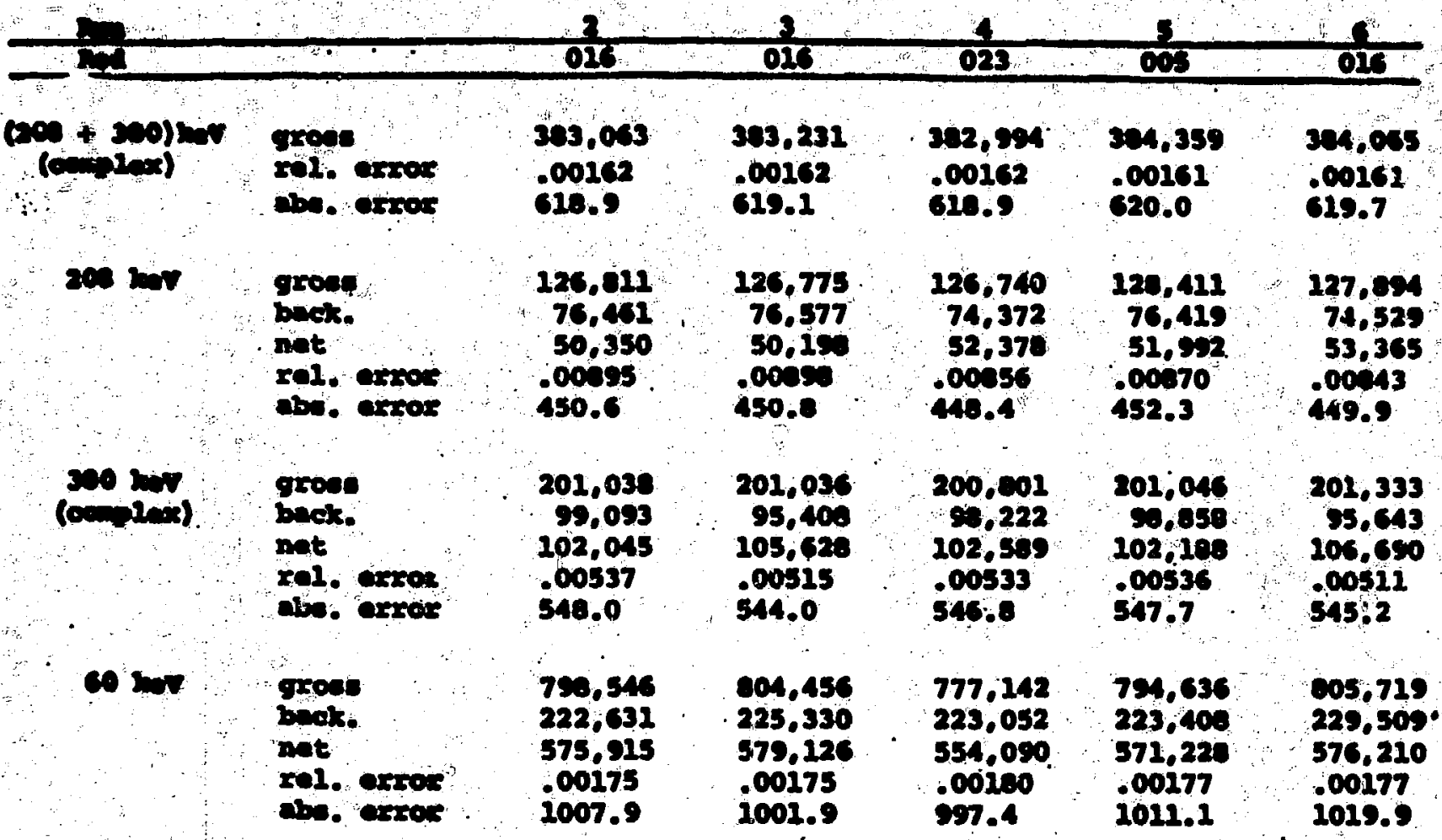


This result, indicating differences in $\mathrm{Am}^{241}$ content was arpriaing since the material for the pellets was known to come from one master blend. The explanation may be that wile the original feed material was thoroughly mixed, the precipitation of the oxide from the nitrate solution was carried out in separate batches, and that small differences In some process parameter caused somowhat different amounts of $\mathrm{Am}^{241}$ to be carried down with the precipitate. A ofmpler explanation is simply the lack in uniformity of wall thickness of the cladding from one rod to the noxt. The 60-kev peak intenaity is, of course, very sensitive to differences in wall thickness.

Uee of a high resolution Ge detector would made a more dotailed isotopic analyeis possible but the trade-off in counting rate might be too severe to be practical. 


\section{ovenry}

The basic point of this paper is the desirability and oven mecsesity of applying statistical analyais to the data resulting from fual rod scan in order to extract the maximum mount of maningful information. some methods are tentatively proposod (and data from a real industrial situation used as an escomple) to stinulate discuision of this subject:

A wethod (Awova-DYR) has been proposed to anable rod ecunning data to be used to determine the degree of homogenolty of fuil rod loadinge, thus augmenting the usual qualitative or semi-quantitative inopection of the strip chrrt recording. The high statistical precision of the MCA total rod apectrum can be used not only to masure total fuel loading but also to detect certain isotopic differences, poseibly of Interent for proces: control if for no other reason. The possibility of using an autocorrelation technigue to search for imparfections or artifacts of a periodic nature in the fuel rod is indicated although this probajbly If of Initad utility.

Fipklly, experimental data has been used to 1llustrate the estrintion of the effectiveness of the slits in defining the portion of the fuel rod being scanned. 


\section{Acknowledgements}

We wish to acknowledge the cooperation of res, and in particular Kessrs. John Crawford and Ralph Jones, who enabled ivi to make. certain of the referred-to measurements.

Footnotes

(1) The basic equipment was as assombled by Mr. John Crawford, of ars. Exwin.

(2) This recording of a defoctive fuel rod was not taken durling the present exercise, but stens from a wuch older experiment.

(3). The statistical tests to be described here are standard and can be found in many sources; the authors have found the single treatmont in "Introduction to statietice" by k. E. Malpole, Macmillan (1968) to be conventent. 